\title{
Artificialização do solo e Vulnerabilidade Humana em duas zonas sujeitas a processos de erosão costeira: casos de estudo da Costa da Caparica e Espinho (Portugal) *
}

\section{Soil Artificialization and human vulnerability in two areas affected by coastal erosion processes: Costa da Caparica and Espinho, Portugal}

\author{
Iva Pires ${ }^{\circledR, 1}$, João Craveiro ${ }^{2}$, Óscar Antunes ${ }^{3}$
}

\section{RESUMO}

Os processos de erosão costeira são o resultado de uma complexa variedade de factores, naturais e antrópicos. Os usos das zonas costeiras, que são atractivas para uma vasta gama de actividades humanas, têm contribuído para uma maior exposição ao risco de erosão e galgamento oceânico. A avaliação das vulnerabilidades a estes riscos, envolvendo as sensibilidades dos grupos locais, constitui um dos objectivos principais do estudo desenvolvido em duas áreas críticas do litoral Português. A avaliação das vulnerabilidades requer a discriminação da evolução dos usos do solo e das respectivas mudanças demográficas, entre outros factores . Esta análise inclui ainda resultados de entrevistas com interlocutores privilegiados e decisores políticos, considerando que os conflitos ambientais são instigados por interesses localizados, nos territórios afectados, mas também por diferentes percepçóes dos riscos.

Palavras-Chave: Erosão Costeira, Factores antrópicos, Ocupação Solo, Conflitos Ambientais, Percepção do Risco.

\section{ABSTRACT}

The processes of coastal erosion are the result of a complex variety of factors, both natural and anthropogenic. The uses of coastal zones, that are attractive to a wide range of human activities, have contributed to a greater human exposure to the risk of erosion and ocean overwash. The assessment of social vulnerabilities, involving the environmental sensitivities of local groups, is a main objective of the study in two critical areas of the Portuguese coast. The assessment of the vulnerabilities requires the discrimination of land use evolution and demographic changes, among other social factors. This analysis still includes results of interviews to stakeholders and policy makers, considering that environmental conflicts are supported by social interests located in the affected territories, but also by different perceptions of risk.

Keywords: Coastal erosion, anthropic factors, land use, environmental conflicts, risk perception.

\footnotetext{
@ - Corresponding author

1 - Universidade Nova de Lisboa, Departamento de Sociologia, Av. de Berna 26C 1069-061 Lisboa, Portugal. e-mail: im.pires@fcsh.unl.pt

2 - Laboratório Nacional de Engenharia Civil, Núcleo de Ecologia Social, Departamento de Edifícios, Lisboa, Portugal. e-mail: jcraveiro@lnec.pt

3 - Universidade Nova de Lisboa, Departamento de Geografia, Lisboa, Portugal. e-mail: oscarduarteantunes@fcsh.unl.pt
} 


\section{INTRODUÇÃO}

A Avaliação para o Milénio dos Ecossistemas concluiu que $2 / 3$ dos ecossistemas mundiais, desde as áreas húmidas às regiōes costeiras, florestas e solos, estão ou degradados ou foram geridos de forma insustentável (MEA, 2006).

As áreas costeiras ao proporcionarem proximidade a esses recursos foram atraindo populaçôes e actividades económicas transformando-se em áreas densamente povoadas e infraestruturadas e onde se localizam grandes áreas metropolitanas. $\mathrm{O}$ aumento e diversidade das actividades que aí se localizam, ou pretendem localizar-se, podem provocar conflitos de uso quando várias actividades lutam pelo uso e apropriaçáo do espaço nem sempre com possibilidade de co-habitar, como no caso da indústria e do turismo. Estas situações de potencial conflito pelo uso e apropriação de um espaço muito valorizado aumentam quando processos de erosão costeira ameaçam as populaçóes e actividades económicas.

Processos de erosão costeira mais ou menos graves são observados em toda a linha de costa na Europa (Pinto, 2004; EEA, 2006; EUROSION, 2006; EEA, 2010). Reconhecendo a complexidade do problema e o deficit de informação sobre estes processos, as suas causas e potenciais consequências, que afectarão em toda a Europa milhares de pessoas, actividades económicas e grandes infra-estruturas situadas em zonas costeiras, a Uniáo Europeia assumiu-o como um desafio para o qual pretende encontrar respostas. Contudo, "Não existe uma solução legislativa simples para estes problemas complexos. Dada a diversidade das condições físicas, económicas, culturais e institucionais presentes, a resposta deverá ser uma estratégia flexível centrada na resolução dos problemas concretos que existem no terreno. Assim, é necessária uma abordagem territorial integrada e participativa para assegurar a sustentabilidade ambiental e económica da gestão das zonas costeiras europeias, que deverá também ser justa e coesa em termos sociais." (CCE, 2000). Mas a complexidade da situação convoca também uma colaboraçáo mais estreita entre cientistas de diversas origens académicas, tornando-se conveniente a discussão sobre a utilidade de conceitos comuns e a definição dos problemas em análise, nomeadamente entre a ecologia humana que analisa as interdependências entre os sistemas sociais e naturais, a sociologia do ambiente que situa muito mais as questóes de análise no interior dos sistemas sociais, privilegiando o modo como os fenómenos sociais acarretam consequências ambientais e os factos ambientais se traduzem em factos sociais, e as ciências naturais (Miller et al., 2008; Yearly, 2004; Pires, Gibert \& Hens, 2010)

Uma abordagem integrada e interdisciplinar também é necessária pois os processos de erosão costeira resultam de um complexo leque de factores, naturais e antrópicos, porque serão desiguais as vulnerabilidades sociais e territoriais, na exposição aos factores ambientais impactantes e porque são potencialmente geradores de conflitos na provável dissensão entre o interesse geral e os interesses privados.

No entanto, tem-se dado maior relevância à explicaçáo dos factores físicos forçadores e aos impactos e muito menos à vulnerabilidade das populaçóes e à sua capacidade adaptativa à mudança.
Não basta prevenir e executar as medidas ambientais que se julgarem adequadas. É preciso compreender a lógica dos actores em presença e as dinâmicas de mudança social para saber prevenir e melhor estruturar as medidas que, necessárias, não configurem novos focos de conflito e de recurso a tribunais, sendo urgente mitigar as diferenças entre um direito $d o$ ambiente e um direito ao ambiente.

Neste artigo será realizada uma primeira aproximação à análise das vulnerabilidades territoriais e sociais em dois casos de estudos de áreas sujeitas a processos de erosão costeira, a Costa de Caparica e Espinho, numa extensão de $14 \mathrm{~km}$ e $10 \mathrm{~km}$ sucessivamente, ao longo da orla costeira, que fazem parte de uma investigação mais ampla que envolve um terceiro caso de estudo, a Ilha de Faro, que não será aqui considerado por ainda não terem sido realizadas entrevistas.

\section{FACTORES DE PRESSÁO ANTRÓPICA NAS ZONAS COSTEIRAS EM PORTUGAL}

Os processos de erosão costeira resultam de um complexo leque de factores, tanto naturais como humanos, combinados, que têm variado de escala, intensidade e de importância ao longo do tempo. A intensa ocupação das zonas costeiras, a diminuição do carreamento de sedimentos pelos rios em consequência da construçáo de barragens, a artificializaçáo da linha de costa ou a subida do nível médio das águas do mar, são comummente apontados como estando na origem dos processos de mudança que estão a ocorrer (Andrade et al., 2009). Deste conjunto de factores interessa-nos destacar os de origem antrópica, em particular os decorrentes da artificialização das zonas costeiras, densificação de construçóes e alterações que foram sendo introduzidas nos usos do solo.

Num relatório (EEA, 2006) que avalia alteraçóes observadas nas áreas de costa no período de uma década na Europa (1990 a 2000), Portugal é mencionado como tendo sido um dos países Europeus onde o crescimento das áreas urbanas foi mais acelerado (34\%), juntamente com a Irlanda e com a Espanha e onde se observou um maior crescimento da população a residir junto da linha de costa, depois da Irlanda. As alteraçóes de ocupação de solo também são destacadas e Portugal foi o país onde mais área agrícola ao longo da costa e dunas foram perdidas para outros usos, nomeadamente para construçáo urbana ou de infra-estruturas de turismo. $\mathrm{Na}$ Europa, largas extensóes da linha de costa estão a perder a sua resiliência e a tornar-se mais vulneráveis pelo aumento da artificialização e pela preferência que tem sido dada às defesas pesadas em especial em áreas de costa densamente povoadas, por exemplo na Holanda, na Bélgica, na Dinamarca e na costa atlântica da França e de Portugal (EEA, 2006:70).

A zona costeira de Portugal Continental estende-se por $950 \mathrm{~km}$, mas cerca de 1/3 do litoral encontra-se ocupado por edificados urbanos e estruturas industriais e portuárias, apresenta uma enorme diversidade morfológica e concentra a maior parte da população e das actividades económicas (Andrade et al., 2006; Freire et al., 2009). Em resultado da interacção do meio terrestre e marítimo, integra múltiplos recursos naturais e de elevado valor ambiental e apresenta potencialidades específicas exploradas pelas actividades económicas, mas representa também, pela elevada pressão a que está sujeita, uma área de elevada sensibilidade e fragilidade (DGA, 1989: 61). 
Em Portugal, modelos históricos de desenvolvimento favoreceram o litoral em detrimento do interior. Os movimentos migratórios internos que atingiram a sua intensidade máxima entre 1960 e 1973, em direcção às cidades do litoral reforçaram o crescimento das áreas metropolitanas (Fonseca, 1990; Ferrão, 1996) e marcaram definitivamente a tendência para a litoralização da população residente no Continente, concentrada nas duas grandes metrópoles portuguesas (Lisboa e Porto) e num contínuo de ocupaçôes urbanas e cidades intermédias ao longo do litoral.

As maiores densidades populacionais encontram-se no litoral algarvio, situação que se agrava nos períodos de maior procura turística, nas duas áreas metropolitanas e numa faixa litoral entre Aveiro e Viana do Castelo. Situaçóes mais críticas em termos de erosão costeira foram identificadas sobretudo no litoral de costa arenosa, as mais apetecíveis para o turismo de "sol e praia" e onde coincidem maiores densidades populacionais (Figura 1).

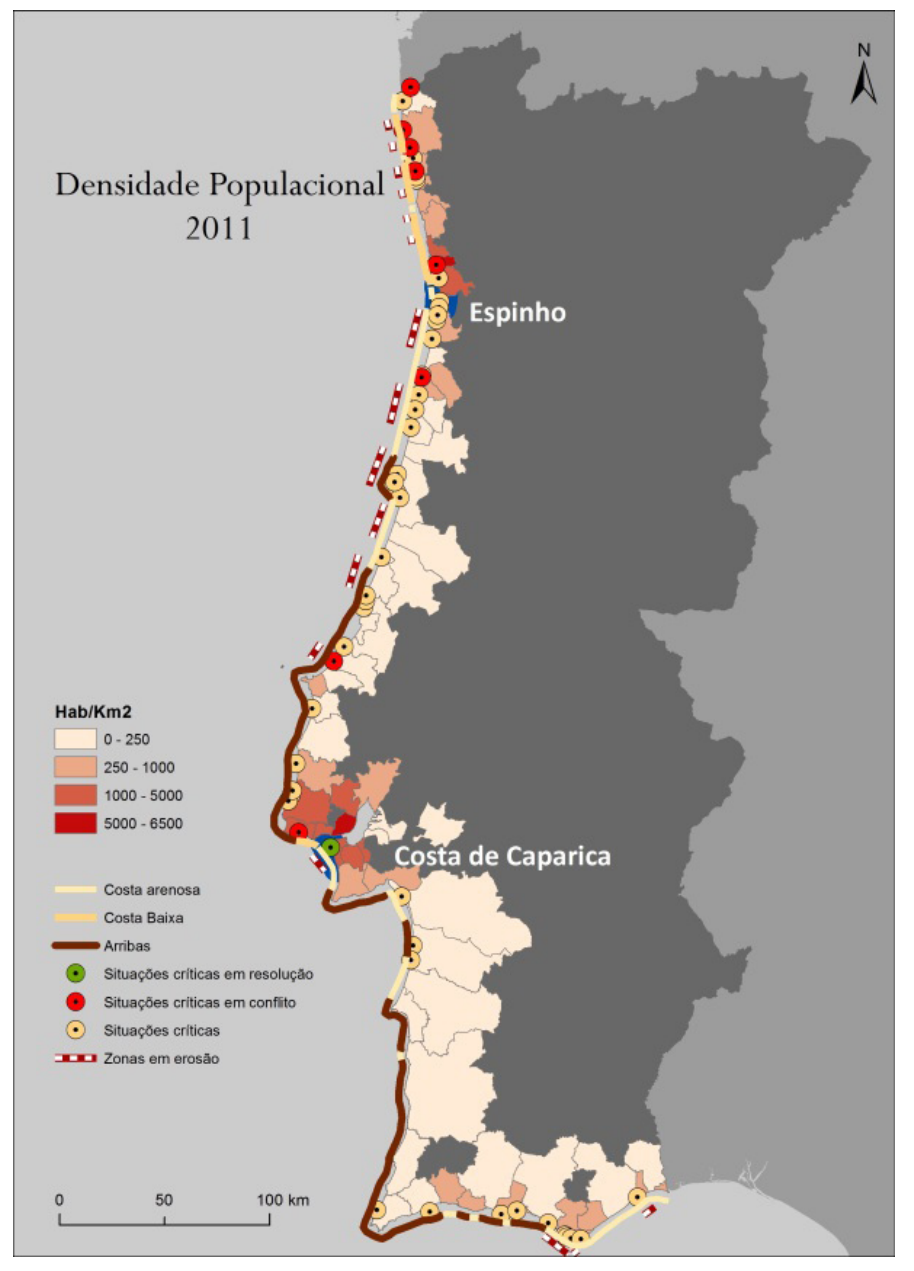

Figura 1. Densidade Populacional nos concelhos da faixa litoral e síntese de situaçóes críticas de erosão da faixa costeira (Programa Finisterra).

Figure 1. Population density in municipalities in the coastal strip and synthesis of critical coastal erosion (Finisterra Program).
Não é só a população a apresentar uma tendência de concentração no litoral, o mesmo aconteceu com o turismo. O turismo emergiu como actividade económica relevante em Portugal na década de 60, quando operadores turísticos estrangeiros descobriram o Algarve e o transformaram num destino privilegiado para a classe média europeia. Os baixos custos (pelo reduzido custo da máo-de-obra e dos preços face ao resto da Europa) transformaram-no num destino acessível para turismo de sol e praia para os trabalhadores qualificados do Reino Unido, da Alemanha e da França, entre outros, o que desencadeou um forte crescimento da oferta. A abertura do Aeroporto Internacional de Faro, em 1965, também contribuiu para transformar o Algarve num destino cada vez mais procurado. A pressáo acentuou-se quando os rendimentos das famílias portuguesas cresceram e o turismo doméstico passou a representar uma fatia importante da procura. A construçáo de infra-estruturas de apoio foi acontecendo de forma desordenada, ao mesmo tempo desqualificando a oferta e alterando significativamente a paisagem.

O turismo representa uma actividade económica relevante, quer na contribuição para o PIB, quer como gerador de receitas e de emprego, mas o seu impacto ambiental e social tem sido frequentemente esquecido (Davenport \& Davenport, 2006; Careto \& Lima, 2007; Simpson, 2009; Claro \& Pereira, 2009). O turismo massificado pode ter consequências disruptivas (e por vezes irreversíveis) nos ecossistemas quer pela alteraçáo do usos do solo que implica, pelo aumento da poluição, do consumo de água, mas também pelo abandono de actividades tradicionais, pela sua sazonalidade (com implicaçóes nos salários baixos e elevada precariedade do emprego) e pela, por vezes brutal, alteração da paisagem com a transformação de pequenas vilas piscatórias em áreas densamente construídas, onde com frequência no verão se ultrapassa a capacidade de carga.

Apesar de estar a perder quota no mercado internacional, pelo aumento da concorrência de destinos mais exóticos a preços acessíveis, o turismo continua a ser uma actividade relevante na economia portuguesa e tem-se assistido mesmo à transição de uma oferta baseada na quantidade e preços baixos para outra baseada na qualidade. A maior parte dos Projectos de Interesse Nacional (PIN) são na área do turismo e em segmentos de elevada qualidade: "Da lista dos projectos PIN de Outubro de 2008, verifica-se que são predominantes os projectos de investimento no sector do turismo, com um valor próximo de $€ 9$ mil milhóes $(64,2 \%$ do total destes projectos), localizados essencialmente em quatro das regióes identificadas pelo Plano Estratégico Nacional de Turismo (PENT) como prioritárias - Algarve, Litoral Alentejano, Alqueva e Oeste (96\%).” (Claro \& Pereira, 2009: 53). Muitos deles vão localizar-se no litoral (como a cidade lacustre Vilamoura XXI, que vai ocupar 850 ha e oferecer 17500 camas) o que implicará ou o aumento da pressão em áreas já sujeitas a elevada pressão ou intervenção em ecossistemas e paisagens até agora preservadas.

No futuro próximo a evolução dos factores antrópicos de pressão será mista. No caso da população, se por um lado se prevê um decréscimo e envelhecimento da populaçáo portuguesa, esta continuará a concentrar-se preferencialmente no litoral e a manter padróes insustentáveis de consumo. Se, 
por um lado, tem sido observada uma melhoria na qualidade das águas balneares e redução dos poluentes, em 2009 só $81 \%$ da população portuguesa tinha sistemas de tratamento de águas residuais (APA, 2011). Em termos de ordenamento do território presta-se maior atenção à especificidade das zonas costeiras, tem-se reforçado a legislação e regulamentação de protecção e as normas impostas às actividades económicas que se localizam nestas zonas. Mas apesar de artificialização das zonas costeiras ser já elevada, considerando as classes de ocupação do solo, as áreas artificiais cresceram $46 \%$ entre 1986 e 2006, prosseguindo a impermeabilizaçâo do solo, tendo sido o tecido urbano descontínuo a componente que mais contribuiu para esta evolução (Freire et al., 2009).

\section{METODOLOGIA}

\subsection{Delimitaçáo e caracterizaçáo da área de estudo}

Para a concretização do estudo, são tidos em conta alguns indicadores que possibilitam a realização da caracterização da populaçáo, do edificado e do uso e ocupação do solo.

Numa primeira fase, a análise abrange toda a linha de costa de Portugal Continental, focando principalmente a densidade populacional (habitante por $\mathrm{km}^{2}$ ) nos municípios com linha de costa bem como as zonas de erosão costeira, a tipologia de costa, arriba, costa baixa ou costa arenosa, bem como o posicionamento de situaçôes críticas, cruzando informação censitária do ano 2001 do Instituto Nacional de Estatística (INE), com a informação do Programa Finisterra, um programa de intervenção na orla costeira continental criado em 2003 com o objectivo de requalificar e reordenar a zona costeira. Partindo do mapa de referência das situaçóes problemáticas na orla costeira continental, elaborado pelo Programa Finisterra, foi acrescentada informaçáo actualizada sobre a densidade populacional nos concelhos com linha de costa (ver Fig. 1 no ponto 2).

Nesta fase de maior abrangência geográfica, a delimitação das duas áreas de estudo começa a ganhar contornos mais definidos, uma vez que nestas áreas localizam-se um elevado número de situaçóes críticas, convergindo com as mesmas áreas geográficas onde se regista um maior valor de densidade populacional por município.

Os três casos de estudo foram seleccionados com base em características socioeconómicas e ambientais distintas, a partir de uma análise de clusters na qual foram consideradas variáveis de carácter "não-social» (medição de zonas de segurança a partir de linhas de água, orografia ou zonas de menor elevação por classes de altitude, e orla costeira por Nomenclaturas de Unidades Territoriais - para fins Estatísticos III (NUTIII)), variáveis sociais relacionadas com a populaçáo (volume e densidade populacionais, graus de concentração urbana, alojamentos familiares, por ex.), e variáveis económicas e ambientais (pessoal ao serviço de empresas, índice de poder de compra, infra-estruturas de ambiente, recursos de saúde e de protecção civil, dinâmicas de construção urbana, entre outras). As zonas costeiras continentais portuguesas podem, assim, ser discriminadas em função de homogeneidades e diferenças estruturais com base num conjunto de variáveis socioeconómicas e ambientais, salientando-se a especificidade da região algarvia e a dinâmica das áreas metropolitanas de Lisboa e Porto (Craveiro et al., 2009).
Deste modo, as 3 áreas seleccionadas recortam situaçóes diferentes tanto do ponto de vista ambiental como socioeconómico, sendo naturalmente a costa Norte, por razóes de dinâmica marítima e exposição aos ventos como por razóes geomorfológicas, mais exposta ao risco natural de erosão costeira. Um caso de estudo recai sobre um troço no Norte de Portugal Continental, abrangendo essencialmente o Município de Espinho, o Município de Almada, na sua frente marítima e adjacente, constitui um segundo caso de estudo (Costa da Caparica) e a Ilha de Faro, no Sul, o terceiro caso de estudo.

Neste artigo iremos abordar apenas dois deles, a Costa da Caparica e Espinho. Desta forma, a área de estudo de Costa de Caparica é limitada a norte pelo aglomerado populacional da Cova do Vapor, e a sul pelo limite da praia da Fonte da Telha, enquanto a área de estudo de Espinho é limitada a norte por Aguda (limite no Clube de Golfe de Miramar), e a sul por Paramos (até ao limite a sul do Aero Clube da Costa Verde). Em comum às duas áreas de estudo, o limite longitudinal corresponde a $500 \mathrm{~m}$ na análise da Base Geográfica de Referenciação da Informação (BGRI), coincidente com o domínio do Plano de Ordenamento da Orla Costeira (POOC), e a $1 \mathrm{~km}$, na análise da Carta de Ocupação do Solo (COS), pelo facto da distância anterior não representar uma significância relevante, adoptando uma metodologia verificada noutros estudos semelhantes (Freire et al., 2009).

O trecho costeiro de Espinho (localizado em costa arenosa), a sul do rio Douro, é uma zona extremamente intervencionada e por isso a sua fisiografia resulta da presença de diversas estruturas de protecção: desde o quebra-mar a norte, na Aguda, passando pelos dois esporôes na frente marítima da cidade de Espinho, até ao campo esporóes a sul, com início em Paramos que se concilia com defesalongitudinal aderente. Já o trecho costeiro da Costa de Caparica (entre a Cova do Vapor e a Fonte da Telha), é caracterizado por litoral baixo e arenoso, em que a largura da planície costeira, entalada entre a arriba fóssil da Costa da Caparica e o mar, se reduz progressivamente de norte para sul. Trata-se de uma planície essencialmente constituída por areias de praia (Cancela et al., 2000), compreendendo dunas litorais pouco expressivas nas zonas naturais. Inclui também dunas frontais fixadas e estruturas de defesa costeira. Este trecho foi, nos últimos 8 anos, alvo de numerosas intervençôes, com vista à redução do risco de erosão e melhoria das condiçóes balneares: reabilitação do cordão dunar, reparação e reforço da defesa frontal, reconstrução de esporôes, enchimento artificial (cerca de $2,5 \times 10^{6} \mathrm{~m}^{3}$ entre 2007 e 2009). Estas situações mais críticas são também comuns para a zona da Costa da Caparica, em troços mais vulneráveis (Praia de S. Joáo e Fonte da Telha), como para a zona de Espinho mais sujeita a uma taxa de erosão de maior expressão, taxa que pode atingir um valor superior a três metros por ano (Careto \& Lima, 2007: 132). Assim, tanto Espinho como a Costa da Caparica experimentam uma larga tradição de protecção costeira com a edificação de obras de defesa da orla costeira que têm privilegiado intervençóes tidas como duras ou intrusivas. Mais recentemente, tem-se ensaiado outro tipo de intervenção, conjugando infra-estruturas anteriores com a alimentação artificial das praias ou uma melhor protecção dos respectivos sistemas dunares. 


\subsection{Ocupaçáo do Solo}

$\mathrm{Na}$ escala de análise de $1 \mathrm{~km}$ ao longo da zona costeira, a partir da linha de preia-mar, é considerado pertinente a análise de um outro indicador, conduzindo à análise da COS. Esta informação, concebida pelo Instituto Geográfico Português, refere-se à ocupação do solo, com uma unidade mínima de 1 ha, sendo produzida com base na interpretação visual de ortofotomapas, que dá origem a uma nomenclatura com vários níveis de informaçáo, que serão detalhados posteriormente. A análise desta informação aborda dois anos, 1990 e 2007 (anos para os quais existe informação disponível), mas coloca o problema de existirem diferenças nas classes entre a COS de 2007 e a de 1990 (Caetano et al., 2009). Foi assim criada uma tabela de compatibilidade (Tabela 1), fazendo uma equiparação entre as classes de ambos os anos, assumindo-se as classes da COS2007 como as guias e adaptando e agregando as classes da COS1990 às do último ano em análise.

A COS2007 caracteriza a ocupação do solo em Portugal Continental com uma nomenclatura hierárquica com 5 níveis, a priori e com 192 classes no seu nível mais detalhado (Caetano, et al., 2008), sendo composta por 5 classes primárias (primeiro nível da nomenclatura da COS): 1-Territórios artificializados, 2-Áreas agrícolas e agro-florestais, 3-Florestas e meios naturais e seminaturais, 4-Zonas Húmidas, e 5-Corpos de água. $\mathrm{Na}$ tabela 1 são apresentadas as classes do segundo nível da COS2007, tendo sido com base nessa nomenclatura que se procedeu à cartografia da alteraçáo da ocupação do solo nos dois casos de estudo.

\subsection{Indicadores de vulnerabilidade}

Existem uma enorme diversidade de abordagens ao conceito vulnerabilidade humana, mas mais do que conflituosas elas são consideradas complementares e essenciais para o estudar na sua complexidade (Eakin \& Luers, 2006; Miller, et al., 2010).

Seguimos a perspectiva que entende a vulnerabilidade com uma construção social e é assim função das condiçôes sociais e das circunstâncias históricas que colocam uma população em risco por exemplo, face a processos de erosão costeira (Dolan \& Walker, 2003). A vulnerabilidade é função de dois atributos, a exposiçáo e a capacidade para lidar com os processos de mudança; esta, por sua vez, depende da resistência, ou capacidade para sofrer impactos e da resiliência, ou seja, da capacidade para recuperar de perdas (cope capacity) depois de um impacto (Turner et al., 2003; Eakin \& Walser (2008).

Entende-se que as vulnerabilidades, na exposição a riscos ambientais, dizem respeito a factores de ordem social (grupos mais vulneráveis ou mais expostos pelas suas características, por factores de idade, menor mobilidade ou outra), económica (actividades mais dependentes de um recurso ou localizaçóes de unidades produtivas em áreas de risco) e geofísica (O’Riordan, 2000: 165). Grupos mais vulneráveis serão aqueles que pela sua posição social e geográfica irão sofrer de forma desproporcionada os impactos negativos (Clark et al., 1998).

Numa revisão de literatura de 128 artigos sobre riscos costeiros e vulnerabilidade humana em países asiáticos os factores relacionados com a demografia estavam entre os mais citados (Zou \& Thomalla, 2008). Geralmente, mais do que um factor contribui para uma situaçáo de vulnerabilidade, podendo factores de fragilidade institucional ou uma menor percepçáo ou sensibilidade face ao risco, por parte das populações e de decisores políticos, agravar as condiçóes em que as comunidades humanas se encontram expostas a eventos prejudiciais de origem natural ou mista. Indicadores como a idade, género, raça, rendimento e recursos materiais, ocupação, condiçôes da habitação, características da família e redes sociais, entre outros, podem ser utilizados para avaliar a vulnerabilidade social (Clark, et al., 1998; Ferreira, 2006; McLaughlin et al., 2002; Nicolodi, 2010; Wu et al., 2002; Dolan \& Wallker, 2003; Cutter \& Finch, 2007, Zou \& Thomalla, 2008). Duma forma mais geral, «a vulnerabilidade coloca em jogo aspectos físicos, ambientais, técnicos, dados económicos, psicológicos, sociais, políticos», não podendo ser totalmente "reduzida a índices científicos ou técnicos» (Veyret, 2007: 40).

Os indicadores utilizados tiveram em conta os estudos referidos e a sua disponibilidade nas estatísticas nacionais, tendo sido recolhidos na sua maioria dos recenseamentos da

Tabela 1. Tabela de Compatibilização entre as classes de ocupação do solo de 1990 e 2007.

Table 1. Table of compatibility between land cover classes of 1990 and 2007.

\begin{tabular}{l|l}
\hline \multicolumn{1}{c|}{ COS_2007 } & \multicolumn{1}{c}{ COS_1990 } \\
\hline Tecido urbano & Espaço Urbano \\
\hline Indústria, comércio e transportes & Infraestruturas e Equipamentos \\
\hline Áreas de extracção de inertes, áreas de deposição de resíduos e estaleiros de construção & Improdutivos \\
\hline Espaços verdes urbanos, equipamentos desportivos, culturais e de lazer, e zonas históricas & Espaços verdes artificiais \\
\hline Culturas temporárias & Terras aráveis-Culturas anuais \\
\hline Culturas permanentes & Culturas permanentes \\
\hline Pastagens permanentes & Prados permanentes \\
\hline Áreas agrícolas heterogéneas & Áreas agrícolas heterogéneas \\
\hline Florestas & Resinosas + Folhosas + Povoamento florestal misto \\
\hline Florestas abertas e vegetação arbustiva e herbácea & Ocupaçấo arbustiva e herbácea \\
\hline Zonas descobertas e com pouca vegetação & Áreas ardidas, dunas, praias, areais, vegetação esparsa, rocha rua, solos sem cobertura vegetal \\
\hline Zonas húmidas interiores & Zonas húmidas continentais \\
\hline Zonas húmidas litorais & Zonas húmidas marítimas \\
\hline Águas interiores & Águas continentais \\
\hline Águas marinhas e costeiras & Águas marítimas \\
\hline
\end{tabular}


população. A informação analisada na BGRI corresponde ao censitário de 2001, uma vez que a do ano censitário de 2011, ainda não estava disponibilizada, à data da realização do estudo, com o mesmo nível de detalhe, contendo apenas valores agregados. Por conseguinte é analisada informação ao nível da subsecção estatística (quarteirão), por várias classes etárias dos indivíduos, famílias, alojamentos de acordo com a sua tipologia e edifícios em consonância com a sua época de construção. Entre vários indicadores calculados e analisados, destacam-se na elaboração deste artigo a tipologia de alojamento, sazonal ou permanente, a idade de construção do edificado, destacando a fase anterior e posterior a 1970, ano do primeiro Relatório do Ordenamento do Território, que privilegia o desenvolvimento económico e social sem ainda evidenciar, no entanto, preocupaçóes relativamente às questóes ambientais (DGOTDU, 2007:2). Este limite temporal foi escolhido tendo também em consideração que em 1974 as condiçóes políticas, sociais e económicas se alteraram em Portugal, esperando-se com o aumento do rendimento das famílias maior acesso à habitação, para residência principal e secundária e portanto uma maior pressão urbanística, nomeadamente nas zonas costeiras. $\mathrm{O}$ ano de 1970 seria assim, em termos estatísticos, aquele que poderia definir o momento antes e depois da Revolução de 1974 permitindo perceber se aumentou, ou não, a pressão urbanística. Em termos demográficos considerámos uma das classes que apresenta uma maior vulnerabilidade, a terceira idade, levando à análise da percentagem da populaçáo com idade igual ou superior a 65 anos, tendo em conta o total da população residente na mesma subsecção estatística.

A elaboração do indicador de vulnerabilidade realizouse conjugando informação socioeconómica, atribuindo ponderações a cada variável, com base na revisão de literatura e no processo de análise hierárquica (Saaty, 2008) numa tentativa de fazer uma aproximação a um índice de vulnerabilidade social robusto. Para a construção do índice são tidos em conta indicadores que traduzam os grupos sociais mais vulneráveis, de forma a que o índice represente geograficamente estas vulnerabilidades.

Elegeram-se sete variáveis socioeconómicas calculadas a partir da BGRI, atribuindo uma percentagem a cada uma de maneira a executar a sobreposição ponderada, levada a cabo a partir do recurso aos Sistemas de Informação Geográfica (SIG). As variáveis e respectivas ponderaçóes foram: índice de envelhecimento $(5 \%)$, taxa de desemprego da população (25\%), taxa de população activa (15\%), taxa de população com 65 ou mais anos (5\%), percentagem de alojamentos sem pelo menos uma infra-estrutura básica (10\%), índice de dependência total $(30 \%)$, e número de edifícios construídos até $1970(10 \%)$.

\section{RESULTADOS E DISCUSSÃO}

\subsection{Alteraçóes no uso do solo}

Numa primeira imagem de conjunto agregando a informação dos dois casos de estudo depreende-se que os territórios artificializados são os que mais crescem neste período, não tanto por causa do tecido urbano em si, mas mais pelo crescimento da área ocupada por espaços verdes, equipamentos desportivos e de lazer, indústria e comércio e infra-estruturas de mobilidade. E isso acontece à custa da reduçáo de área ocupada por culturas temporárias, de agricultura mista e da área florestal (Figura 2).

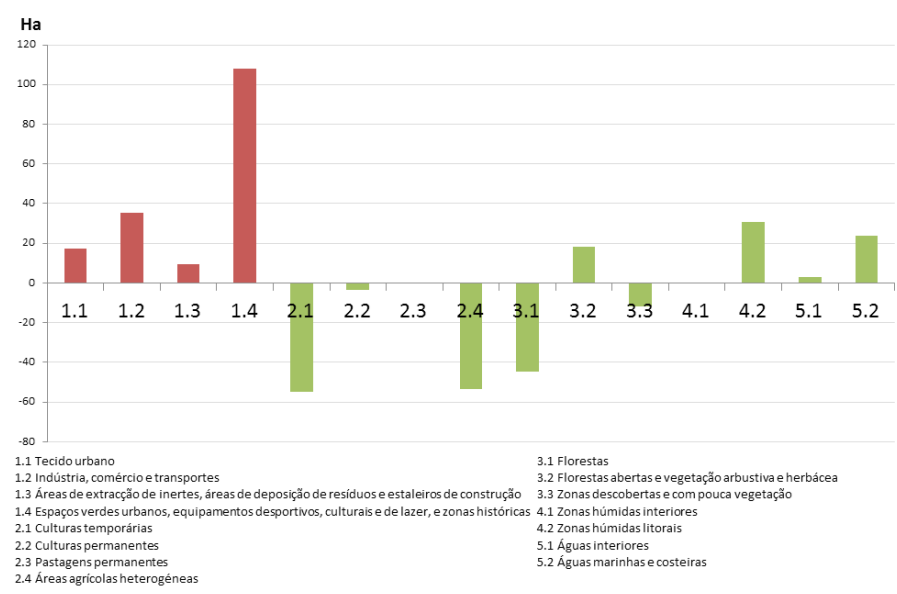

Figura 2. Alteraçáo do Uso do Solo 1990-2007, por principais classes de ocupação.

Figure 2. Land Use Change 1990-2007, by major occupational groups.

A faixa costeira de Espinho é mais intensamente urbanizada do que a da Costa da Caparica e ainda assim continua a densificar-se. Na verdade, o Plano Regional de Ordenamento do Território do Norte (PROT-Norte) refere que os territórios artificializados cresceram nesta região, ente 1985 e $2000,48 \%$, ou seja acima da média do país, de $42 \%$ e sobretudo em resultado de um padrão de urbanização difuso mas que resultou também numa densa ocupação humana nas zonas costeiras. Um outro estudo que utilizou a informação da Corine Land Cover (CLC) mostrou que a artificialização do solo no primeiro quilómetro a partir da linha de costa era, em 2000, mais elevado na Região Norte (41\%), apesar de ter tido o maior crescimento no Algarve desde 1990 (Freire, et al., 2009). A proximidade à linha de costa sujeita as populações e as actividades económicas a maior vulnerabilidade tendo em conta a situação de recuo dessa linha (Partidário, et al., 2009:42) pelo que se propóe "Contribuir para a desconcentração urbana nas zonas costeiras, em articulação com o POOC de Caminha-Espinho, nomeadamente através do estabelecimento de alternativas estratégicas à pressão urbanistica nestas zonas. Desenvolver, em articulação com o POOC Caminha-Espinho, um sistema de qualificação das praias consideradas estratégicas por motivos ambientais ou turisticos, definindo critérios de ocupação sustentável nas suas envolventes" (Partidário et al., 2009:180).

A progressão das áreas artificializadas é visível em ambos os casos entre 1990 e 2007, (figuras 2 e 3) e isso acontece em resultado de 3 processos: preenchimento de interstícios ainda não ocupados em áreas já bastante artificializadas; "abertura" de novos processos de urbanização em áreas ainda não artificializadas; e prolongamento, ao longo da linha de costa, para norte e para sul, de áreas já urbanizadas. 
A primeira situação é mais evidente em Espinho, o que confere a esta mancha urbana ainda maior densidade pela expansão à custa do desaparecimento de pequenas áreas de cultura temporária, incapazes de competir com a pressáo imobiliária decorrente da procura de residências secundárias.

$\mathrm{Na}$ costa da Caparica essa área de culturas temporárias (Terras da Costa), que se situa entre a mancha urbana e a arriba fóssil, apesar de pressionada pela expansão urbana, parece estar a resistir melhor ao avanço da construçáo.

Parte da situação de caos urbanístico e de degradação dos recursos ambientais da Costa da Caparica também decorre das excelentes condiçôes de oferta balnear e da sua proximidade e a boa acessibilidade à Área Metropolitana de Lisboa (AML) que a transformaram numa área privilegiada de lazer tanto para a população da margem norte, em especial após a construçáo da Ponte 25 de Abril, em 1966, como para a da margem sul. $\mathrm{O}$ período de maior crescimento populacional ocorreu na década de 70 e correspondeu também ao período de maior aumento da construção de fogos (legal e clandestina), e de parques de campismo para residência fixa e secundária (Plano Estratégico do Polis da Costa da Caparica, 2001). Nessa década a urbanização ocorreu entre o núcleo antigo (edifícios predominantemente construídos até à década de 70) e a linha de costa que passa a ser densamente urbanizada. Em 2007, a sul da Costa da Caparica é evidente o crescimento do tecido urbano na Fonte da Telha e, a norte, a abertura de uma nova frente urbana com a urbanização de São João.

Pela sua excelência em termos de oferta balnear e pela necessidade de preservar o ambiente natural a Costa da Caparica mereceu um programa de requalificação urbana e ambiental, nomeadamente para valorização das praias e da frente urbana litoral, no contexto do Programa Polis, do Ministério das Cidades, Ordenamento do Território e Ambiente. Embora não totalmente concluído (20012009) as intervençóes realizadas no âmbito deste programa contribuíram para valorizar a Costa da Caparica e oferecer mais qualidade de vida aos residentes e de fruição aos turistas. Com responsabilidade do Instituto da Água (INAG) foram também aprovadas 3 fases de alimentação artificial das praias urbanas da costa da Caparica e de Sáo João. O projecto teve início em 2007 e desde essa altura já foram colocados vários milhóes de metros cúbicos de areia nestas praias mas a intervenção de 2011 não chegou acontecer.

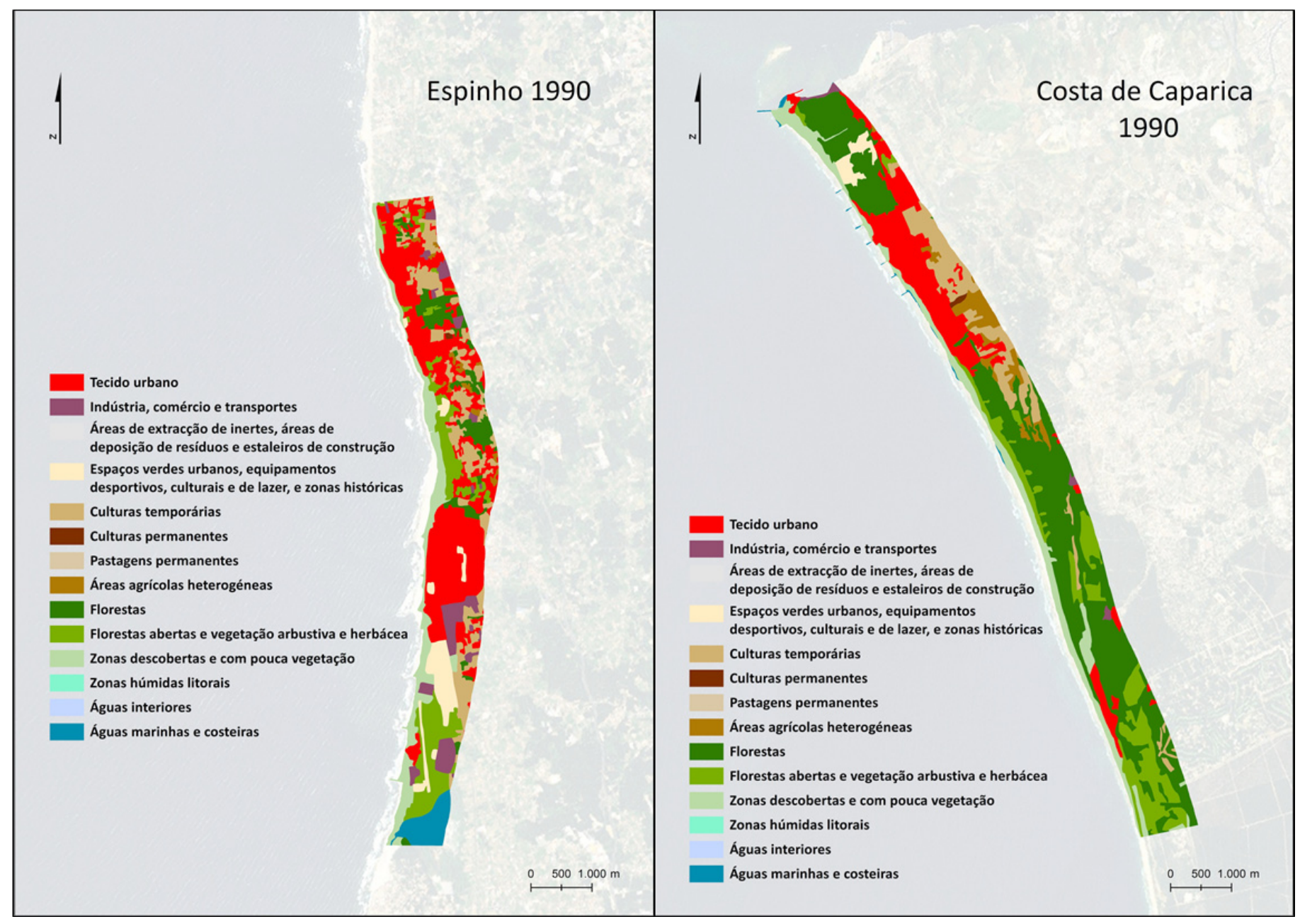

Figura 3. Uso do Solo, por principais classes de ocupação, na Costa da Caparica e em Espinho, 1990.

Figure 3. Land Use, by major occupational groups in Costa da Caparica and Espinho, 1990. 


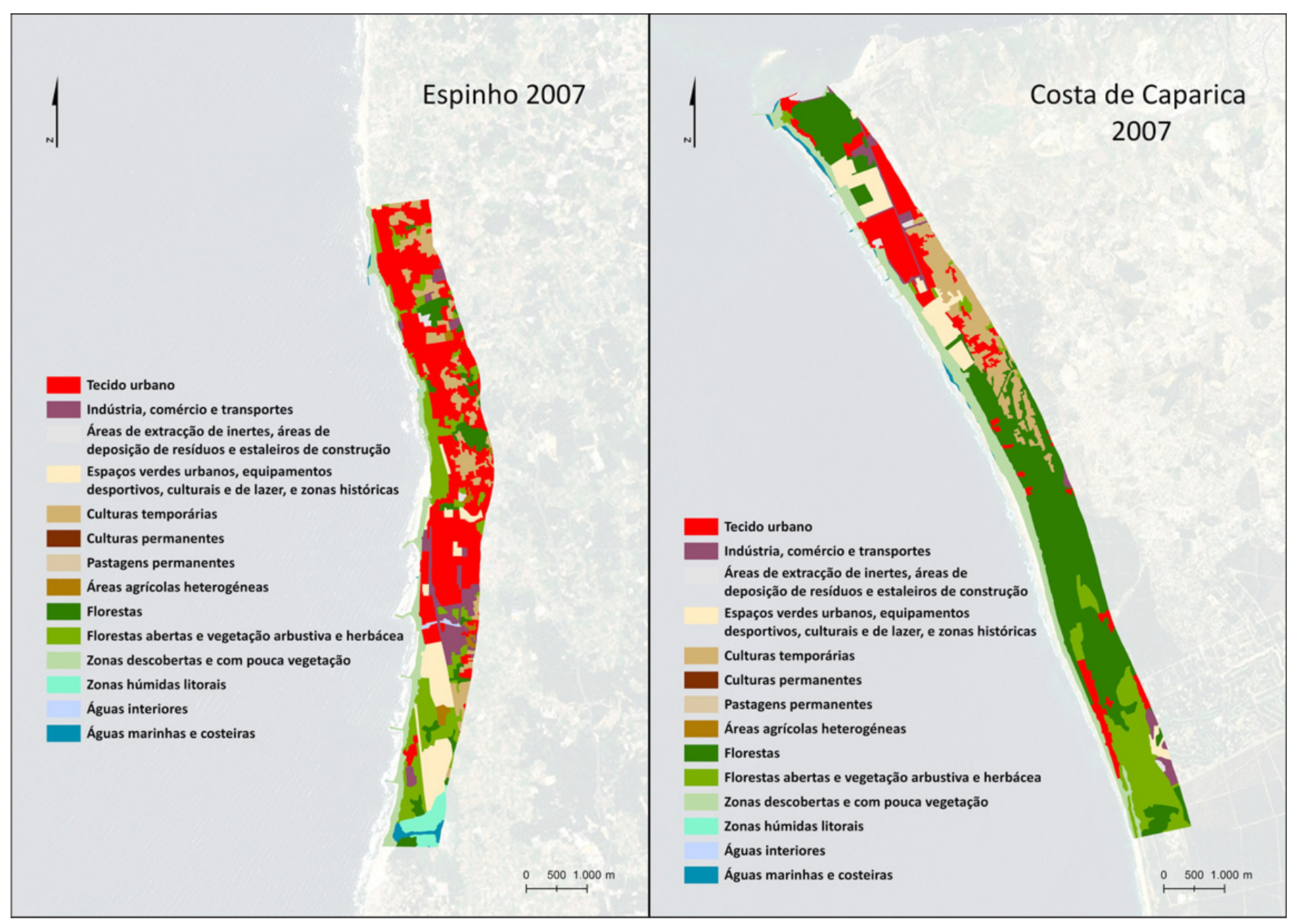

Figura 4. Uso do Solo, por principais classes de ocupação, na Costa da Caparica e em Espinho, 2007.

Figure 4. Land Use, by major occupational groups in Costa da Caparica and Espinho, 1990.

Estas variaçóes de uso do solo, no sentido da artificialização (para habitação e lazer, para zonas de serviços e novos espaços industriais ou para infra-estruturas de apoio à mobilidade) que ocorrem num curto intervalo de tempo e a poucos metros da orla costeira, mais reforçam as questôes da resiliência e da aprendizagem no âmbito de se encontrarem soluçóes sustentáveis, e respostas políticas adequadas, face ao risco de erosão costeira. A existência de múltiplas entidades com responsabilidades, nem sempre excludentes, sobre a gestão das zonas costeiras, desde o nível local às autoridades nacionais, o excessivo academismo na formatação de políticas com a subsequente subestimação das potencialidades da participação pública, e perda de inter-perspectivas derivadas das percepçôes científicas e das percepções comuns sobre os riscos ambientais traduzem-se em menor capacidade adaptativa, menor reanimaçáo dos processos de decisão e menor eficácia na reorganização das respostas institucionais às ameaças ambientais, o que se traduz, em poucas palavras, na reprodução de um sistema sócio ecológico pouco resiliente (Miller et al., 2008).

\subsection{Vulnerabilidade social da populaçáo residente em áreas sujeitas a processos de erosão costeira}

Uma primeira aproximação à análise das vulnerabilidades sociais e territoriais foi ensaiada, tendo em conta a escala dos casos de estudo, por área de costa e um zonamento de cerca de 500 metros para o interior, tal como referido na explicação metodológica. Mas deve desenvolver-se para além dos indicadores de caracterização dos territórios de risco passando a envolver também as racionalidades socioeconómicas que os preenchem, a própria percepçáo do risco de uma série de actores sociais e os mecanismos políticos de protecção civil e de accionamento das políticas ambientais. Como introdução à questão das vulnerabilidades, nas 2 áreas de estudo, optouse por georreferenciar algumas variáveis censitárias que dizem respeito a dimensôes fulcrais da exposição humana aos riscos ambientais: características da população, do espaço humanizado e dos seus usos. Com base na unidade habitaçấo, neste nível de análise, relaciona-se uma população mais idosa (com 65 ou mais anos de idade) com residências de construçáo mais antiga e usos do edificado (para fins habituais ou 
sazonais de residência), tendo-se também recorrido a outras variáveis disponíveis para a escala do quarteirão. A título de exemplo, os dados mostram a discriminação da população idosa e as zonas onde é mais abundante, residindo em zonas extremamente sensíveis ao risco de erosão e nos edifícios mais antigos, construídos maioritariamente antes de 1970, o que é bem notório tanto em Espinho como na Costa da Caparica. Em ambos os núcleos urbanos a populaçáo é bastante envelhecida, em alguns quarteirōes a populaçáo com 65 ou mais anos representa entre $40 \%$ a $60 \%$, chegando em alguns quarteiróes a representar mais de $80 \%$.

A sobreposição ponderada das 7 variáveis socioeconómicas de caracterização da populaçáo residente permitiu obter uma primeira imagem do grau de vulnerabilidade social da população residente na Costa da Caparica e em Espinho que deverá, posteriormente, ser complementado com indicadores de vulnerabilidade física e avaliação de risco desenvolvidos por outros estudos (Ferreira, 2006) (Figura 5 e Figura 6).

As vulnerabilidades atrás referidas interagem com a noção de risco e esta está relacionada com uma percepção elementar do perigo que se encontra associado a algo que se desconhece. Vários autores assinalam uma diminuiçáo do

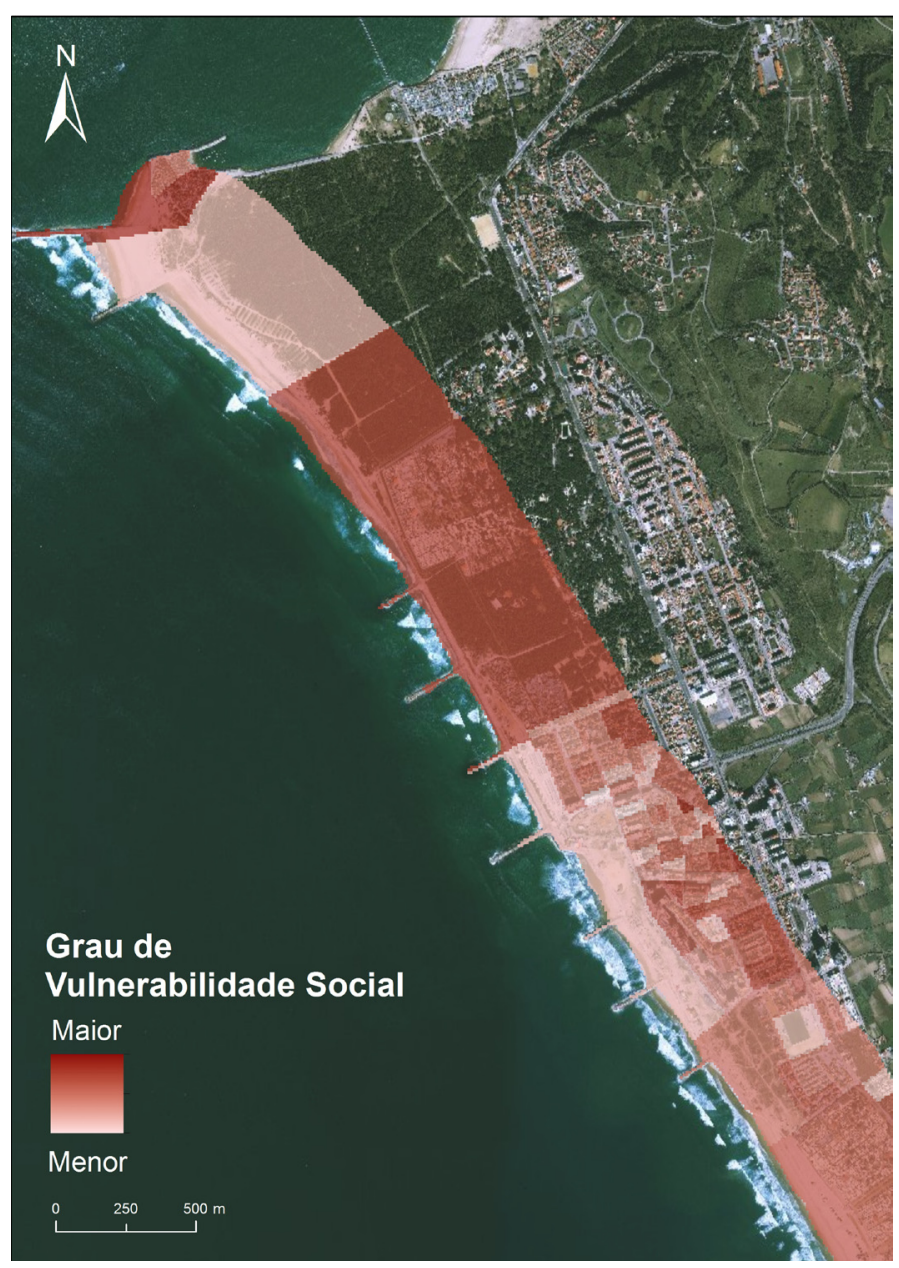

Figura 5. Vulnerabilidade Social da População Residente junto à linha de costa, Costa da Caparica.

Figure 5. Social Vulnerability of the Inhabitants near the coastline, Costa da Caparica.

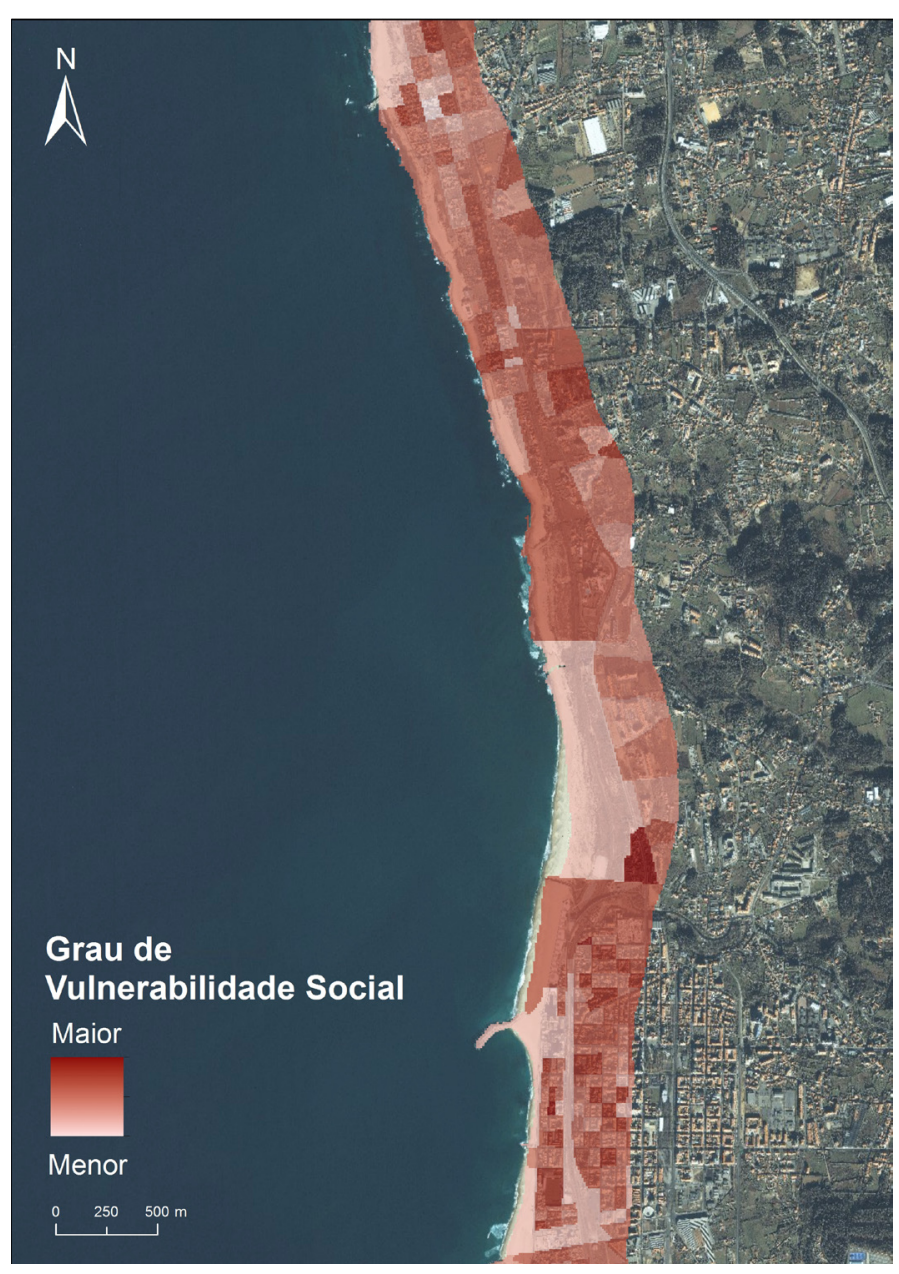

Figura 6. Vulnerabilidade Social da População Residente junto à linha de costa, Espinho.

Figure 6. Social Vulnerability of the Inhabitants near the coastline, Espinho.

risco percebido como resultado da exposição continuada a situações de perigo que não têm trazido, por casualidade, consequências visíveis, de modo repetitivo (Halpern-Felsher et al., 2001; Silva \& Lima, 1997). Em Portugal, os estudos sobre as questóes ambientais publicados nos últimos anos indicam que também há uma aparente diminuição da percepção do risco como resultado de uma insensibilização com origem na exposiçáo continuada a situações de risco (Lima, 2004).

A vulnerabilidade está igualmente relacionada com a capacidade dos actores sociais para lidar com processos de mudança, para se organizarem e encontrar soluçóes, preferencialmente colectivas, gerirem potenciais conflitos, ou seja, para criar as condiçóes para uma gestão sustentável dos riscos ambientais. Por gestão sustentável dos riscos ambientais entende-se uma forma de governação dos territórios de modo a encontrar um equilíbrio de longo prazo entre os factores de desenvolvimento socioeconómico das populações e a mitigação das ameaças da escassez ambiental ou dos eventos extremos, devendo-se atender ao potencial intrínseco do conflito (Craveiro, 2007: 124). 
A questẫo do conflito recoloca, aliás, a questâo da eficácia do Estado numa nova ordem política conjugada com a governação ou a participaçáo activa dos cidadãos e dos seus grupos de interesse (Bredariol e Vieira, 2006: 33), devendo assim a participação pública integrar os processos de gestão sustentável dos riscos.

$\mathrm{O}$ entendimento que os residentes têm dos processos de erosão costeira será aferida com recurso a uma classificação de conteúdos resultantes da participação do público em instrumentos de ordenamento do território para a protecção e valorização das zonas costeiras. Os relatórios de participação pública na discussão dos POOC discriminam os agentes que participaram, a título individual ou institucional, sendo interessante confrontar os tipos de argumentação desenvolvida pelos diversos agentes. Mas fundamentalmente a consulta dos POOC sustentou a selecçáo de interlocutores privilegiados e forneceu uma primeira aproximação ao sistema de actores, dando a perceber a valorizaçáo das questóes geradoras de conflito ou consenso e o número e natureza das instituiçóes envolvidas, como do tipo de questóes que os particulares apresentaram de forma nominal. O projecto RENCOASTAL privilegia a realização de entrevistas exploratórias e outras técnicas de auscultação directa das populações ou grupos vulneráveis (sessões com grupos focais) e a inquirição por frentes marítimas urbanas, em zonas de risco.

Foram, assim, realizadas entrevistasa um sistema de actores, residentes, representantes de interesses específicos, gestores e decisores sobre os diferentes tipos de intervenção (intrusivas ou colaborativas) para a defesa das zonas costeiras e das actividades humanas nelas situadas. Entre Julho e Setembro do ano de 2011 realizaram-se 25 entrevistas exploratórias, envolvendo essencialmente a Costa da Caparica e 2 em Espinho, ao Presidente da Câmara Municipal e ao Presidente da Junta de Freguesia de Paramos. A maior incidência na Costa da Caparica prende-se com o facto de se constituir como palco privilegiado de conflitos (a propósito dos Parques de Campismo e das recentes intervenções de valorização urbana e de protecção costeira, prevendo-se a deslocalização dos referidos Parques e tendo-se consolidado uma ocupação do sector da hotelaria e restauração, assim como a inibição de aspectos tradicionais associados à arte xávega de tracção motora, em plena praia, de redes de pesca). Auscultaramse 23 entidades na Costa da Caparica (destacando-se associaçóes ligadas a actividades empresariais da restauração, com 6 entrevistas, e entidades de representação política ou autoridades locais, igualmente com 6 entrevistas, mais 4 entrevistas a dirigentes de associaçóes de surf e campismo, 3 a associaçóes de moradores, 1 a sindicato de pescadores e 2 a associaçóes de interesses culturais sobre a defesa das tradiçôes locais, sobretudo com a protecção da arte xávega e do tipo de construção de apoio à actividade da pesca). As restantes entrevistas serviram como pontos de aferição para os outros casos de estudo, prevendo-se para breve contactos mais intensivos em Faro e Espinho, no sentido de explorar a realização de reuniốes com pescadores (grupos focais), como na Costa da Caparica.

As entrevistas exploratórias incidem sobre temas gerais, sobre as causas e consequências da erosão costeira, e algumas questóes específicas sobre a identificação das zonas de risco na Costa da Caparica e a equidade na distribuição dos custos e medidas adaptativas. Os resultados auxiliam, neste momento, a estruturação de um inquérito a lançar em frentes marítimas urbanizadas nos casos de estudo, e extraem-se questóes críticas para a reunião com os grupos focais. $\mathrm{O}$ guião da entrevista discrimina-se em perguntas sobre a evolução da linha da costa (percepção da erosão costeira ao longo dos anos e eventos danosos), causas e consequências, assim como uma avaliação social sobre medidas de protecção, papel das entidades envolvidas e os valores ou interesses a proteger.

Uma das questôes gerais sobre a percepção das causas («em seu entender quais são as principais causas da erosão costeira?») indicia um fraco conhecimento sobre as mesmas, atribuindo-se a responsabilidade ao mar, e ao seu cíclico comportamento ( Sempre existiram maresias e temporais, o mar entrava pela terra porque não havia nada para o suster, por essa razão foi feita a muralha», conforme avança um representante de pescadores na Costa da Caparica ou, de acordo com as palavras de um dirigente de uma associação em defesa da arte xávega e dos chamados palheiros dos pescadores, "Somos casas de praia, não de campo nem de cidade. Quando falamos em recuar queremos dizer recuar a distância necessária para estarmos salvaguardados do avanço do mar. Que para nós nunca foi preocupação [o avanço do mar] porque já estamos habituados»).

Relativamente a causas antrópicas, é abundantemente referido no local, pelos pescadores e associaçóes de interesses culturais, a extracção de areias entre a Trafaria e o Bugio, o que segundo a opiniâo recolhida veio agravar a vulnerabilidade da Costa da Caparica à agitação marítima, embora o mar continue sempre a ser o principal agente responsável («tínhamos uma grande ilha de areia, mas com as obras da Expo e com as obras feitas em Oeiras [...]", representante dos pescadores). Outra causa antrópica referida é a construção em altura e a ocupação urbana sobre a orla costeira, o que se entende pela oposiçáo entre um estilo de vida mais tradicional e comunitário e o destino das zonas costeiras, objecto de férias massivas e lugar adensado por novas construçóes urbanas («Nós como pescadores acreditamos que a construçấo pesada dá origem à erosão, porque a Sul da costa da Caparica, temos as dunas e as praias praticamente intactas, e aí não houve construção pesada", mesmo dirigente de pescadores).

Relativamente às consequências é quase sempre referido o recuo das áreas de praia, mas náo a inundação de zonas habitacionais consolidadas, uma vez que tem competido às entidades estatais a protecção de pessoas e bens, custe o que custar, defendendo-se a solução extrema do amuralhamento, onde for necessário, como em frente à zona mais densamente urbanizada. Contudo, os pescadores criticam a edificação sobre a "muralha», com "bunkers», numa alusão clara aos novos restaurantes da linha da Costa da Caparica, e acentuam mais uma vez a relação, apesar de espúria, entre a construção urbana e a erosão costeira (a retenção de sedimentos, por obras hidráulicas ao longo do leito dos rios, tem contribuído muito mais para a erosão costeira, enquanto causa provocada pela acção humana;a construção humana representa, mais, um sinal de vulnerabilidade e de exposição ao risco que um factor de causa).

Por seu turno, proprietários da restauração argumentam em favor da valorização urbana da Costa, como tem acontecido, salvo no que diz respeito à questão do areal 
que devia merecer uma maior alimentação artificial, para se evitarem "comentários negativos» de quem visita a Caparica (como referido por um proprietário de um dos novos restaurantes). Regista-se, aqui, a potência conflitual entre interesses, e entre formas de ocupação do território (entre casas antigas de pescadores, sobretudo na Fonte da Telha, mais a ocupação a Norte para campismo e as novas construçóes para restauração, sobre a muralha, e as novas unidades hoteleiras). Está também em causa um sentido de equidade ambiental na distribuição dos danos e custos derivados da erosão costeira e das medidas de protecção. Neste sentido, a actividade de campismo parece claramente prejudicada ( $\mathrm{O}$ paredão está mesmo a ceder, não vai aguentar muito mais tempo [...], estamos preocupados porque, mesmo em frente ao Parque, a água chega lá de certeza nas marés vivas; Em Novembro passado [2010] a água entrou, um pouco no parque pela primeira vez»: dirigente de Parque de Campismo). Também a actividade da pesca, por escassez de praia (as redes costumavam ser arrastadas para terra com tractores na praia ou tracção animal) e proibiçóes sucessivas sobre essas práticas se sente afectada.

Contudo, quanto à urgência de protecção não se detectam dissensôes locais, antes a percepção unânime (por parte dos representantes de interesses económicos ou culturais) que compete ao Estado tomar medidas, embora o sentido dessas medidas deva estar conformado à defesa das ocupaçóes e actividades existentes. A visão de responsáveis políticos mais próximos das populaçôes (representantes de Juntas de Freguesia) não difere destas apreciações gerais. Segundo um dos autarcas locais, "Existe um recuo de costa efectivo, e existe outra coisa que é a subida de nível dos Oceanos, e estas duas coisas em conjunto são explosivas. Ou se entra por uma defesa costeira pura e dura, ou então estamos sujeitos a que a resistência que será oferecida à violência do mar seja de curta duração".

Apenas dirigentes de organismos do poder central desenvolvem uma apreciação menos comprometida com as expectativas locais, e uma valorização ambiental que, em último recurso, apela directamente à contribuição das populaçóes locais, não se inibindo de se defender uma taxa de litoralização ou a proibição de novas construçóes. Por seu lado,os representantes de interesses locais ou de associaçôes culturais rejeitam custear soluçóes adaptativas, cabendo essa tarefa às entidades centrais.

No entanto, o número total das entrevistas realizadas não é suficiente para estruturar oposiçōes mais vincadas, constituindo-se como uma primeira aproximação aos actores no terreno e ferramenta de extracção de questôes críticas para as fases de inquirição que estão em preparação. Estas questóes críticas reportam-se aos modelos de desenvolvimento urbano e ao balanço entre os factores ambientais e os interesses locais. Estes interesses locais argumentam pela defesa intransigente de medidas adaptativas que impliquem a não cessaçáo de actividades e a permanência da ocupação urbana. A valorização destes factores sociais contraria soluçóes adaptativas que envolvam a relocalização de actividades e o recuo de formas de ocupação, como no caso das ocupaçóes amovíveis e construçóes com materiais menos resistentes (Parques de Campismo e palheiros), denotando-se já aqui a presença de uma conflitualidade aberta com recurso à judicialização dos direitos de uso e ocupação adquiridos.

Estão em causa, assim, apreciaçôes de ordem social associadas à equidade ambiental, pois as intervençóes levadas a cabo no território acabam por favorecer uns e afectar negativamente outros. Este sentimento de desigualdade em relação à distribuição dos custos ambientais e alterações programadas de uso e ocupação dos territórios é, como ilustrado atrás, mais marcante entre ocupaçóes menos estruturantes e actividades menos pesadas e as outras actividades que se julgam promovidas pelas políticas urbanas e formas de protecção costeira (novos locais de restauração sobre estrutura de protecção, maior segurança contra inundaçóes para zonas urbanas consolidadas).

Estas consideraçóes não são extrapoláveis para os outros casos de estudo (Espinho e Faro), mas suportam uma análise dos conflitos ambientais baseada no antagonismo de interesses e na percepção dos impactos sociais das alterações das condições ambientais assim como das medidas de protecção costeira. Apenas o aprofundamento dos momentos de inquirição e do contacto directo com grupos locais pode (melhor) fundamentar que a agudização dos conflitos ambientais resulta da sobreposição entre vulnerabilidades sociais e desfavorecimentos ambientais, como consequência quer da agitação marítima e recuo da linha da costa quer como produto das opçóes adaptativas que, eventualmente, valorizam (ou acabam por valorizar numa primeira fase) os aspectos económicos ligados ao turismo e a segurança das ocupaçóes urbanas mais densas e consolidadas em detrimento de ocupaçóes amovíveis e actividades do sector primário. Deste modo, é igualmente importante, para o projecto em curso, aprofundar a metodologia da construção estatística de índices de vulnerabilidade, jogando com diversos factores sociais, geomorfológicos e da agitação marítima, incluindose igualmente como factor de ponderação a percepção social do risco. Neste caso, e como resultado das entrevistas exploratórias, a indisponibilidade dos grupos locais para o custeamento de soluçóes adaptativas e de protecção costeira deve ser entendida como indicador de vulnerabilidade social, entre outros associados a ocupaçóes territoriais e condiçóes habitacionais.

\section{CONCLUSÓES}

As comunidades abrangidas pelo projecto são potencialmente vulneráveis às consequências da erosão costeira não só porque vivem em áreas onde estes processos de erosão estão activos mas também pelas formas de ocupação humana e dependência das actividades face a condições de amenidade ambiental. Apela-se, de forma geral, a uma forte intervençáo do Estado no desenvolvimento de medidas de protecção da orla costeira, solicitando um tipo de intervenção pesado por parte da engenharia civil, em desfavor de outros investimentos ou opçóes adaptativas. No entanto, a crise económica actual pode conduzir à não disponibilização de verbas e ao adiar de soluçóes. A erosão costeira caracteriza-se por ser um risco gradual e progressivo, exigindo que se adoptem medidas mitigadoras (o recuo das formas de ocupação humana é uma medida possível) e não apenas adaptativas, de reforço de estruturas pesadas de protecção ou de reparação dos danos. Aliás, crê-se que os 
custos reparadores serão extremamente mais elevados, tendo em conta que a remediação dos danos é mais onerosa que o desenvolvimento de acçốes preventivas.

Há, contudo, que conciliar interesses sociais e dependências ambientais, requerendo-se mecanismos de auscultaçâo social e a identificação de vulnerabilidades. As políticas de ordenamento do território são mais sensíveis à gestấo dos riscos naturais e induzidos, enquanto certamente se densificam regulamentaçóes técnicas na senda de alertas sobre as alteraçôes climáticas e os riscos ambientais, mas o carácter potencial dos conflitos ambientais não deve ser subestimado

Refira-se que um dos objectivos do projecto é não apenas o estudo dos conflitos, e das formas de regulação ambiental, mas também contribuir para o desenvolvimento de uma maior sensibilidade ambiental, através da ponderação de factores de vulnerabilidade, e reuniōes com grupos sociais e responsáveis por interesses locais. Crê-se que asustentabilidade ea resiliência das zonas costeiras não dispensam a percepçáo do risco pelas populaçóes, mas a questão essencial parece prender-se com a equidade ambiental e os impactos sociais das medidas a adoptar Outra questão a explorar nos próximos momentos de inquirição, como com maior pormenor na ponderaçáo de factores para a construção de índices de vulnerabilidade, diz respeito ao confronto de soluçóes mitigadoras e adaptativas, entre perspectivas de intervenção mais pesada ou menos intrusiva.

O risco de erosão costeira caracteriza-se por uma acção combinada, entre factores naturais e sociais, de exposição humana gradual e progressiva, registando-se um importante diferimento entre as causas (múltiplas e dispersas no espaço e no tempo) e a visibilidade dos danos. Este diferimento dificulta também, por um lado, uma assunção mais clara da consciência do risco, e do sentido da responsabilidade humana. Por outro, o acentuar de factores de incerteza sobre alteraçôes climáticas e soluções futuras parece desfavorecer investimentos mais urgentes, e debates mais alargados sobre as formas de prevenção e protecção da orla costeira.

Finalmente, parece ainda ressaltar uma forte correlação entre os interesses sociais defendidos, na dependência das suas localizaçốes no território, e os argumentos invocados. Deste modo, embora os conflitos ambientais se expressem por novos factores de desigualdade e náo estruturem, necessariamente, uma oposição inter-classista (uma vez que a dependência ambiental das actividades é determinante por sobre as posiçóes socialmente estratificadas), estes conflitos reproduzem ainda o estafado argumento clássico (o ser determina a consciência) que associa intimamente a experiência dos actores sociais ao seu tipo de discurso e acção.

A exploração das dependências ambientais e da percepção do risco devem igualmente pesar na construção de índices de vulnerabilidade, para além das variáveis tradicionais ligadas a condiçóes sociais ou demográficas, assim como a existência de estruturas de protecção costeira. A experiência dos actores reflecte-se também na percepção do risco e deve condicionar a posição face a medidas de prevençáo e protecção, dimensóes que merecem uma melhor exploração no âmbito do projecto.
Ressalve-se, ainda, que a erosão costeira e, duma forma geral, a sustentabilidade das formas de humanização dos territórios reforçam elementos de incerteza perante um futuro que permanece, em si, indeterminado. Acentuamse, pois, dimensóes de conflito associadas à disputa dos factores de favorecimento e à visibilidade imediata das formas de protecção face aos riscos ambientais, com recurso a intervençóes pesadas que são as que melhor sufragam o sentimento de segurança.

\section{BIBLIOGRAFIA}

Andrade, C.; Pires, H.; Silva, P. (2006) - Zonas Costeiras. In: E.D. Santos \& P. Miranda (eds.), Alteraçóes Climáticas em Portugal: Cenários, Impactos e Medidas de Adaptação. Projecto SIAM II, pp.169-206, Projecto SIAM II, Gradiva, Lisboa, Portugal. ISBN: 972-662-843-1. Disponível em http://siam.fc.ul.pt/siamII_pdf/SIAMII.pdf

Andrade, F; Cabral, H.; Borges, M.F. (2009) - Ambientes Costeiros. In: Henrique Miguel Pereira, Tiago Domingos, Luís Vicente e Vânia Proença (eds.), Ecossistemas e Bem Estar Humano, Avaliação para Portugal do Millenium Ecossystem Assessement, pp.413-435, Escolar Editora, Lisboa, Portugal. Disponível em http://ecossistemas.org/ ficheiros/livro/Capitulo_12.pdf.

APA (2011) - Relatório de Estado do Ambiente 2011. 200 p., Agência Portuguesa do Ambiente, Lisboa, Portugal. ISBN: 9789728577599. Disponível em http://sniamb. apambiente.pt/docs/REA/rea2011.pdf

Bredariol, C.; \& Vieira, L. (2006) - Cidadania e Política Ambiental. 171 p., Record Editora, Rio de Janeiro, ISBN: 8501052655.

Caetano, M.; Nunes, V.; Araújo, A. (2008) - Concepção e desenvolvimento das especificaçóes técnicas da nova Carta de Ocupação do Solo de Portugal Continental. 20 p., Atas do X Encontro de Utilizadores de Informação Geográfica (ESIG 2008), Oeiras, Portugal. Disponível em http://www.igeo.pt/gdr/pdf/Caetano2008_ESIG08_ ID14.pdf

Caetano, M.; Nunes, V.; Pereira, M. (2009) - Land Use and Land Cover Map of Continental Portugal for 2007 (COS2007): project presentation and technical specifications development. 3rd Workshop of the EARSeL Special Interest Group on Land Use / Land Cover, 12 p., Bonn, Germany. Disponível em http://www.igeo.pt/gdr/ pdf/Caetano_2009_EARSEL.pdf

Cancela, J.; Afonso, J.M.; Rebolo, L.; Barros-Gomes, H.; Teles, M.; Barata, A. (2000) - POOC Sintra-Sado. Seminário A Zona Costeira de Portugal, Os Planos de Ordenamento da Orla Costeira, pp.109-123, Associação EUROCOAST-Portugal, Lisboa, Portugal.

Careto, H.; Lima, S. (2007) - Turismo e Desenvolvimento Sustentável. 294p., Geota, Lisboa, Portugal. ISBN: 9789728898-090.

CCE (2000) - Parecer do Comité das Regióes sobre: a "Comunicação da Comissáo ao Conselho e ao Parlamento Europeu relativamente à Gestão Integrada da Zona Costeira: uma estratégia para a Europa", e a "Proposta de recomendaçáa do Parlamento Europeu e do Conselho relativamente à execução da Gestão Integrada da Zona 
Costeira na Europa» (2001/C 148/07). Jornal Oficial no C 148 de 18/05/2001 p.0023-0025. http://eur-lex.europa. eu/LexUriServ/LexUriServ.do?uri=OJ:C:2001:148:0023 :0025:PT:PDF

Clark, G.; Moser, S.; Ratick, S.; Dow, K.; Meyer, W.; Emani, S.; Jin, W.; Kasperson, J.; Kasperson, R.; Schwarz, H. (1998) - Assessing the Vulnerability of Coastal Communities to Extreme Storms: The case of Revere, MA., USA. Mitigation and Adaptation Strategies for Global Change, 3(1):59-82, DOI: 10.1023/A:1009609710795.

Claro, M.A.; Pereira, M.A. (2009) - Alteraçóes Climáticas e Turismo - uma questão em aberto. Departamento de Prospectiva e Planeamento e Relaçóes Internacionais, Ministério do Ambiente, do Ordenamento do Território e do Desenvolvimento Regional, Documento de Trabalho No 1/2009, 114p., Lisboa, Portugal. http://www.dpp. pt/Lists/Pesquisa\%20Avanada/Attachments/1122/ alteracoes_climaticas.pdf

Craveiro, J. (2007) - O Homem e o Habitat: Território, Poderes Públicos e Conflitos Ambientais. 344 p., Laboratório Nacional de Engenharia Civil, Lisboa, Portugal. ISBN: 9789724921044

Craveiro, J.; Oliveira, T.; Pereira, A. (2003). Valorização e Protecção da Zona Costeira Portuguesa. Relatório Final. Componente Factores Sociais, económicos e de planeamento urbanistico. 62p., Laboratório Nacional de Engenharia Civil, Lisboa, Portugal.

Craveiro, J.;, Pires, I.;, Almeida, I.;, \& Antunes, O. (2009) - Zonas Costeiras continentais portuguesas: Questóes prévias sobre a ecologia humana das Zonas Costeiras e os conflitos pelo seu uso e a regulação dos territórios. REvCedoua (Revista do Centro de Estudos de Direito do Ordenamento, do Urbanismo e do Ambiente) (ISSN: 08741093), 24(2):119-126, Coimbra, Portugal

Cutter, S.; Finch, C. (2007) - Temporal and spatial changes in social vulnerability to natural hazards. PNAS - Proceedings of the National Academy of Sciences, 105(7):2301-2306. DOI: $10.1073 /$ pnas.0710375105.

Davenport, J.; Davenport, J.L. (2006) - The impact of tourism and personal leisure transport on coastal environments: A review. Estuarine, Coastal and Shelf Science, 67(1-2):280292. DOI: $10.1016 /$ j.ecss.2005.11.026

DGA (1989) - Relatório de Estado do Ambiente (REA). 190 p., Ministério do Ambiente e Ordenamento do Território, Lisboa, Portugal.

DGOTDU (2007) - Relatório do Programa Nacional da Politica de Ordenamento do Território (PNPOT). Anexo à Lei n.o 58/2007, de 4 de Setembro, que aprova o Programa Nacional da Politica de Ordenamento do Território (PNPOT), rectificado pelas declaraçóes n.o 80-A, de 7 de Setembro de 2007 e n.o 103-A/2007, de 2 de Novembro de 2007. 155 p., Ministério do Ambiente, do Ordenamento do Território e do Desenvolvimento Regional, Lisboa, Portugal. Disponível em http://www.territorioportugal. pt/pnpot/Storage/pdfs/PNPOT_Relatorio.pdf

Dolan, A.H.; Walker, I.J. (2003) - Understanding vulnerability of coastal communities to climate change related risks. 8 p., Journal of Coastal Research, SI 39 (Proceedings of the 8th International Coastal Symposium): 1317-1324. Disponível em http://cip2008.cip-icu.ca/_ CMS/Files/dolan.pdf.
Eakin, H.; Luers, A. (2006) - Assessing the Vulnerability of Social-Environmental Systems. 32 p., Annual Review Environmental Resources, 31:365-94. DOI: 10.1146/ annurev.energy.30.050504.144352

Eakin, H.; Walser, M.L., (2008) - Human vulnerability to global environmental change. In: Encyclopedia of Earth. pp. 302-317, Eds. Cutler J. Cleveland. Disponível em http://www.unep.org/geo/geo3/english/pdfs/chapter3_ vulnerability.pdf

EEA (1995) - The Dobris Assessment, Europe's Environment, State of the environment report, Directorate-General for the Environment, European Commission No 1, Copenhagen, Denmark. ISBN: 92-826-5409-5.

EEA (2006) - The changing faces of Europe's coastal areas. EEA - European Environment Agency, Report No 6/2006, 107p., Copenhagen, Denmark. ISBN: 9291678422. Disponível em http:/www.eea.europa.eu/publications/ eea_report_2006_6/at_download/file

EEA (2010) - The European environment: state and outlook 2010. Synthesis. 222p., European Environment Agency, Copenhagen, Denmark. ISBN: 978-92-9213-114-2. Disponível em http://www.eea.europa.eu/soer/intropage/ synthesis/synthesis/at_download/file

EEA(1999) - State and pressures of the marine and coastal Mediterranean environment. 137 p., Environmental Issues Series, n5, Office for Official Publications of the European Communities, Copenhagen, Denmark. ISBN: 92-9167-164-9.

EUROSION (2006) - Viver com a Erosão Costeira na Europa. Resultados do Estudo Eurosion. 38p., Serviço das Publicaçóes Oficiais das Comunidades Europeias, Luxemburgo. ISBN: 92-79-02209-1. Disponível em http://www.eurosion.org/project/eurosion_pt.pdf

Ferrão, J. (1996) - A Demografia Portuguesa. 63 p., Cadernos do Público, Lisboa, Portugal.

Ferreira, J.C. (2006) - Coastal zone vulnerability and risk evaluation: A tool for decision-making (an example in the Caparica Littoral - Portugal). Journal of Coastal Research, SI 39 (Proccendigs of the 8th International Coastal Symposium): 1590-1593. Disponível em http://siaiacad09. univali.br/ics2004/arquivos/334_ferreira.pdf

Fonseca, M. L. (1990) - População e território. Do país à área metropolitana. 416 p., Memórias do Centro de Estudos Geográficos, nº14, CEG, Lisboa, Portugal. ISBN: 9726360951.

Freire S.; Santos T.; Tenedório, J.A (2009) - Recent urbanization and land use/land cover change in Portugal - the influence of coastline and coastal urban centers. Journal of Coastal Research, SI 56 (Proceedings of the 10th International Coastal Symposium):, 1499-1503. Lisbon, Portugal. Disponível em http://e-geo.fcsh.unl. pt/ICS2009/_docs/ICS2009_Volume_II/1499.1503_S. Freire_ICS2009.pdf

Halpern-Felsher; B.; Millstein, S.; Ellen, J.; Adler, N.; Tschann, J.; Biehl, M. (2001) - The role of behavioural experience in judging risks. Health Psychology, 20(2):120126, DOI: 10.1037/0278-6133.20.2.120.

Holling, C.; Gunderson, L. (2002) - Resilience and adaptative change. In Lance H. Gunderson \& C.S. Holling (eds.), Panarchy: understanding transformations in human and 
natural systems. pp.25-62, Island Press, Washington, EUA. ISBN: $1559638575,9781559638579$.

Huber, J. (2005) - Towards Industrial Ecology: Sustainable Development as a Concept of Ecological Modernization. In: Michael R. Redclift \& GrahamWoodgate (eds.), New Developments in Environmental Sociology, pp.269285, Cheltenham: Edward Elger, originally publisged in Journal of Environmental Policy \& Planning (2000), 2:269-285. Disponível em http://www.eve.ucdavis.edu/ catoft/eve101/Protected/PDF/lit/Huber_2000.pdf

Lima, M.L. (2004) - On the influence of risk perception on mental health: living near an incinerator. Journal of Environmental Psychology, 24(1):71-74., DOI: 10.1016/ S0272-4944(03)00026-4.

McLaughlin, S.; McKenna, J.; Cooper, J. (2002) - Socioeconomic data in coastal vulnerability indices: constraints and opportunities, Journal of Coastal Research. SI36 (ICS 2002 Proceedings): 487-497. Disponível em http://www. science.ulst.ac.uk/ics2002/mclaughlin_s\%20et\%20al.pdf

MEA, (2006) - UNEP in 2006. Millenium Ecosystem Assessment. 87 p., Millenium Ecosystem Assessment, United Nations Environment Programme, http://www. unep.org/pdf/annualreport/UNEP_AR_2006_English.pdf

Miller, T.R.; Baird, T.D.; Littlefield C.M.; Kofinas G.; Chapin III, F.S.; Redman, C.L. (2008) - Epistemological Pluralism: Reorganizing Interdisciplinary Research. Ecology and Society (ISSN: 1708-3087), 13(2):46, Wolfville, Nova Scotia, Canada. Disponível em http://www.ecologyandsociety. org/vol13/iss2/art46/ES-2008-2671.pdf

Miller, F.; Osbahr, H.; Boyd, E.; Thomalla, F.; Bharwani, S.; Ziervogel, G.; Walker, B., Birkmann, J.; van der Leeuw S.; Rockström , J.; Hinkel, J.; Downing, T.; Folke, C.; Nelson, D., (2010) - Resilience and Vulnerability: Complementary or Conflicting Concepts?. Ecology and Society, 15(3) 11. Disponível em http://www. ecologyandsociety.org/vol15/iss3/art11/

Nicolodi, J.; Petermann, R. (2010) - Mudanças Climáticas e a Vulnerabilidade da Zona Costeira do Brasil: Aspectos ambientais, sociais e tecnológicos, Revista da Gestão Costeira Integrada 10(2):151-177. http://www.aprh.pt/ rgci/pdf/rgci-206_Nicolodi.pdf

O'Riordan, T. (2000). Environmental Science for Environmental Management (2nt edition). 520 p., Prentice Hall: Harlow, England. ISBN: 0582218896.

Partidário, M.R.; Vicente, G.; Augusto, B.; Valentim,M. (2009) - Avaliação Ambiental Estratégica. 198 p., Plano Regional de Ordenamento do Território do Norte, CCDRN e IST, Lisboa, Portugal. Disponível em http://consulta-protnorte.inescporto.pt/plano-regional/avaliacao-ambientalestrategica/RA_AAE\%20PROT-N_25_06_2009.pdf.

Partidário, M.R.;, Vicente, G.;, Augusto, B.R.;, Belchior, C.; Nespen, S.U.;, Martins, R.; Santos, P.C.;, Frade, S.;, Lima, J. (2010) - Avaliação Ambiental Estratégica da Alteraçấo do Plano Regional de Ordenamento do Território da Area Metropolitana de Lisboa, Relatório Ambiental. 275p., IST - Instituto Superior Técnico / PROTAML - Plano Regional de Ordenamento do Território da Área Metropolitana de Lisboa, Lisboa, Portugal. Disponível em http://consulta-protaml.inescporto.pt/plano-regional/ avaliacao-ambiental-estrategica/Relatorio-Ambl-AltPROTAML.pdf
PENT, (2007) - Plano Estratégico Nacional do Turismo. 137 p., Ministério da Economia e da Educação, Turismo de Portugal, Lisboa, Portugal. Disponível em http://www.turismodeportugal.pt/Portugu\%C3\%AAs/turismodeportugal/Documents/Plano\%20Estrat\%C3\%A9gico \%20 Nacional\%20Turismo.pdf

Pinto, F.T. (2004) - The practice of coastal zone management in Portugal. JournalofCoastal Conservation, 10(1):147-158. DOI: 10.1652/1400-0350(2004)010[0147:TPOCZM]2.0.CO;2

Pires, I.; Gibert, M.M.; Hens, L. (eds.) (2010) - Studies in Human Ecology., 259p., Liber Amicorun C Susane, M. Nazareth, Ph. Lefeure-Witier, International Centre for Human Ecology, Publishing House for Science and Technology, Ha Noi, Vietnam.

Saaty, Thomas L. (2008) - Decision making with the analytic hierarchy process. International Journal of Services Sciences, 1(1):83-98. DOI: 10.1504/IJSSCI.2008.017590.

Silva, S.; Lima, M.L. (1997) - Positive illusions related to dam risks. In: A. Betâmio de Almeida \& T. Viseu (eds.), Dams and Safety at Downstream Valleys, pp. 123-126, A.A. Balkeme, Roterdão, Holanda.

Simpson, M. (2009) - Integrated approach to assess the impacts of tourism on community development and sustainable livelihoods. Community Development Journal, 44(2):186-208. DOI: $10.1093 / \mathrm{cdj} / \mathrm{bsm} 048$

Turner II, B.L.; Kasperson, R.E; Matson, P.A; McCarthy, J.J; Corell, R.W; Christensen, L.; Eckley, N; Kasperson, J.X; Luers, A.; Martello, M. L.; Polsky, C.; Pulsopher, A.; Schiller, A. (2003) - A framework for vulnerability analysis in sustainability science., Proceedings of the National Academy of Sciencespp. 8074-8079, PNAS July 8, vol. 100( no. 14):8074-8079., DOI: 10.1073pnas. 1231335100.

Veyret, Y. (2007) - Os Riscos: o Homem como Agressor e Vitima do Meio Ambiente. 320p., Editora Contexto, São Paulo. ISBN: 9788572443548

Wu, S-Y.; Yarnal, B.; Fisher, A. (2002) - Vulnerability of coastal communities to sea-level rise: a case study of Cape May County, New Jersey, USA. Climate Research, 22: 255270. DOI: $10.3354 / \mathrm{cr} 022255$.

Yearley, S. (1996) - Sociology, Environmentalism, Globalization.: 161p., Sage Publications, London, U.K. ISBN: 0803975171.

Zou, L; Thomalla, F. (2008)- The Causes of Social Vulnerability to. Coastal Hazards in Southeast Asia. Stockholm Environment Institute, Working Paper, 90 p., Stockholm, Sweden. ISBN: 978-91-86125-15-8. Disponível em http://www.sei-international.org/mediamanager/ documents/Publications/Sustainable-livelihoods/social_ vulnerability_coastal_hazards_thomalla.pdf 